\title{
Speed Control of PMDCM Based GA and DS Techniques
}

\author{
Wisam Najm AL-Din Abed, Adham Hadi Saleh, Abbas Salman Hameed \\ Department of Electronic Engineering, College of Engineering, University of Diyala, Iraq
}

\begin{tabular}{l}
\hline Article Info \\
\hline Article history: \\
Received Jan 27, 2018 \\
Revised Aug 23, 2018 \\
Accepted Sep 15, 2018 \\
\hline Keyword: \\
Genetic algorithm \\
Output derivative controller \\
Pattern search \\
Performance indices \\
Permanent magnet motors
\end{tabular}

\section{Corresponding Author:}

Wisam Najm AL-Din Abed,

Department of Electronic Engineering,

College of Engineering,

University of Diyala, Iraq.

Email: wisam_alobaidee@yahoo.com

\begin{abstract}
Permanentmagnet dc motors (PMDCM) are extensively used in several applications like, various medical applications, technologies for space applications, computers, robotics, military field, electric automobiles, etc. In this article, MATLAB software is used for designing and modelling of the PMDCM. Output derivative controller is proposed for controlling the motor speed because of its improving capability of system damping. For enhancing the performance of the proposed controller, its parameters are optimized based genetic algorithm (GA) and direct search (DS) strategies. Different performance criteria are used in controller tuning process. The obtained results from the proposed evolutionary strategies are compared. The work results show clear enhancement in the controller performance by improving the PMDCM transient and steadystate performance for all used performance indices.
\end{abstract}

Copyright $@ 2018$ Institute of Advanced Engineering and Science. All rights reserved.

\section{INTRODUCTION}

The motors that operate from dc source are extensively used in various industrial applications, because of its own good adantages like high starting-torque, satisfy response performance, good speedcontrol response, extensive speed control variety. It is widely applicable in different speed-control systems that required high control necessities [1]. PMDCM belong to dc-motors family which used in various applications due to its simple structures, high efficiency and lower cost. This type of motors is applied when essentialy required variable motor operation with high-speed. The field winding absence of this motor, make it low cost, simple structure, lower starting-torque, slight noise, lower culosses which lead to increase its efficiency. High performance dc- motor service PMDCM which needs accurate complex trajectory-tracking especially for position speed reference, with enhanced steady-state and transient behaviour. In modern power electronics, electric drives control represent one of the chief topics. [2]. The tuning process of conventional controllers faces major challenges and difficulities especially under variable loading conditions. These challenges is due to parameters variation and irregular operation modes[3].

Recently, Multiple Objective Evolutionary techniques have established to be special suitability for solving various problems [4]. GA and DS strategies represents a special type of DS named pattern search (PS) [5]. PS is a sub-class of DS algorithms introduced by Torczon for problems with unconstrained parameters and extended by Lewis and Torczon to constrained problems with boundaries [6]. In 1975, John Holland was originally produced GA technique. GA are a random global-search strategy. It represents natural evolution process imitation [7].

Many researchers focus on the control of DC motors, due to its advantages like good speed-torquecharacteristics, simple controlarrangement and it can be used in different applications due to its wide variety. For controlling the DC-motors, different controllers ranging from conventional PIDs to advanced control algorithms [8]. PID controller have simple structure, reialization and ease of use. These PID controller 
advantages make it to play an important role in feedback control system.

But, the main problems of the these controllers are the derivative and proportional kick effects that gives large system overshoot and oscillation specially in the load disturbance prescence [9]. This disadvantage of PID controllers appear to be an actual problem faces the closed-loop control-system designing for dc motors systems.

In this article, the proposed solution is to design output derivative controller-based DS and GA strategies for tuning the controller parameters. The motivation that urges us to use output derivative controller originate from the fact that, output derivative controller doesn't generate plant zero also doesn't reduce system order (or system dynamics increase). output derivative controller generates system stiffest, lower sensitivity to disturbance. Also, it has the effect of attenuation which leads to decrease the percent overshoot and enhance system performance. DS and GA strategies are proposed for controller parameters tuning optimally. These strategies have various advantages like simple search method, optimal search area scan, need low algorithm parameters and avoid local optima entrapment. These advantages make them good effective optimization methods.

Greatest number of reasearchers give attention to traditional PIDs controller application in dcmotor control using various optimization method. In 2014 Singh et. Al., [10] present PID-controller based GA for speed control of dc drive. In 2014 Ibrahim et. Al., [11] introduce Ant Colony Optimization (ACO) tuning PID controller to control separated excited dc motor speed. In 2014 Ibrahim et. Al., [12] proposed PID controller optimized based Bacterial Foraging (BF) and Particle swarm optimization (PSO) strategies for dcdrive speed control. In 2015 Diego et. Al., [13] introduce PID controller based ACO to control the motor speed in robotic arm. While in 2016 Suman and Giri [14] present GA method for PID controller tuning for speed control of dc motor. In 2016 Abdulameer et. Al., [15] propose conventional tuning methods for PID controller tuning. In 2018 Shamseldin et. Al., [16] propose BLDC motor speed control arrangement using nonlinear PID controller based GA.

\section{PMDCM MODEL}

PMDCM is used in various applications due to its advantages like safety, good stability, lowe cost, easy control arrangement required low voltages run ability. The PMDCM mathematical model is comes from its electrical and mechanical equations (see Equ.(1) to (5)) [17]:

$$
\begin{aligned}
& V_{a}(t)=R_{a} i_{a}(t)+L_{a} \frac{\mathrm{d} i_{a}(t)}{\mathrm{d} t}+E_{b}(t) \\
& E_{b}(t)=K_{b} \cdot \omega_{m}(t) \\
& T_{m}(t)=K_{t} \cdot i_{a}(t) \\
& K_{t}=K_{b}=k \\
& T_{m}(t)=J_{m} \frac{\mathrm{d} \omega_{m}(t)}{\mathrm{d} t}+B_{m} \omega_{m}(t)+T_{L}(t)
\end{aligned}
$$

$\mathrm{E}_{\mathrm{b}}$ is the rotor emf $(\mathrm{V})$.

$\mathrm{R}_{\mathrm{a}}$ is rotor resistance $(\Omega)$.

$V_{a}$ is rotor voltage (volt).

$\mathrm{i}_{\mathrm{a}}$ is the rotor current (ampere).

$\mathrm{K}_{\mathrm{b}}$ is the constant of rotor emf (V.s/rad).

$\mathrm{K}_{\mathrm{t}}$ is the constant of torque (N.m/A).

$\mathrm{J}$ : moment of inertia (kg.m).

$\mathrm{L}_{\mathrm{a}}$ : rotor inductance $(\mathrm{H})$.

$B_{m}$ : coefficient of viscous friction (N.ms/rad).

$\mathrm{T}_{\mathrm{m}}$ : mechanical-torque (N.m).

$\omega_{\mathrm{m}}$ : motor speed $(\mathrm{rad} / \mathrm{s})$.

$\mathrm{T}_{\mathrm{L}}$ is the output-torque (N.m). 


\section{OUTPUT DERIVATIVE CONTROLLER}

Output derivative controller can be implemented by internally feedingback the plant output signal derivative. This can be done using tachogenerator. Then comparing the internally derivative signal with a proportional error signal (Figure1) [18]. This controller type doesn't generate plant zero while some other controllers do this. So this controller doesn't increase the system overshoot. This means the controllerenhance the system damping [19].

1.

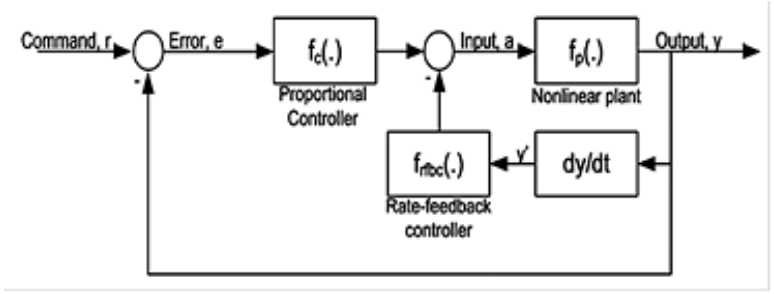

Figure 1. Output derivative controller scheme [20]

\section{DS AND GA OPTIMIZATION TECHNIQUES}

DS method is one of the most important optimization methods. It has the ability for function minimization by comparision method. It does not require any derivative information. As well as, it does not build derivative approximation. Pattern search (PS) methods can be regarded as a DS technique [21]. PS is suitable for solving various optimization problems that lie outside the search. It has simple concept, easy implemention and have efficient computation process. PS has good balanced operator for improving and adjusting the global local search area. This method begins by generating points set named mesh, surrounding the current point. This point could be the point of initial starting that given by the operator or it could be calculated from the preceding algorithm step. By adding pattern (set of vectors) to the current point, the mesh is formed. The algorithm flowchart is iilustrated in Figure2[22].

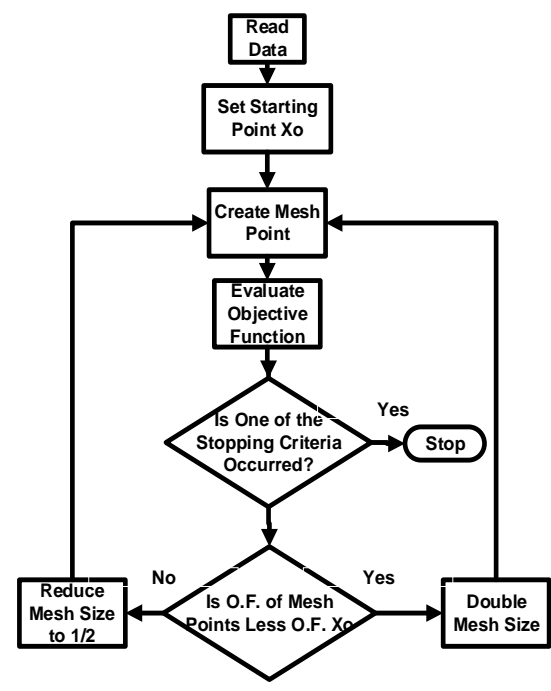

Figure 2. PS algorithm flow chart

GA is an exploration technique emulates the natural-selection process. It involves of three steps, i.e., reproduction, crossover, and mutation[23]. It is a powerful well-known random evolutionary search method. There are three elementary difference between GA and other traditional optimization techniques. First, GA works on the parameters of the problem that encoded strings (each string represent problem single solution). Then the parameters value can be obtained by decoding these strings. Second, GA have the ability to 
discover the search-space effectively and simultaneously. This feature makes GA decreasing the probability of being local points entrapment. Third, GA does not need previous data from the problem search area. It is elementary to compute objective function only. GA have the ability to solve both constrained and unconstrained problems[24].

GA were originally proposed by John Holland (1975). GA algorithm stages are illustrated as follows: 1) Define Population Size

In this step the algorithm initial population is generated. It is normally about 20-100 individuals. 2) Reproduction

This step specifies the regeneration of the next population. The probability of chromosome to survive related to its fitness value. Where fitness is chromosome suitability survive measure[25]. During the reproduction step, the chromosome fitness value is estimated. The cost function value is used in the selection stage to give bias towards appropriate chromosome. It is similar to evolution process in nature, a fit chromosome has a higher selection probability and can be selected for reproduction step.

3) Crossover

The step comes after selection step. New individulas is generated by pairing previous individuals. 4) Mutation

It is a stochastic process in natural evolution. It have the ability to produce new individuals by changing a part of individual gene [7]. GA steps are clarified in Figure. 3.

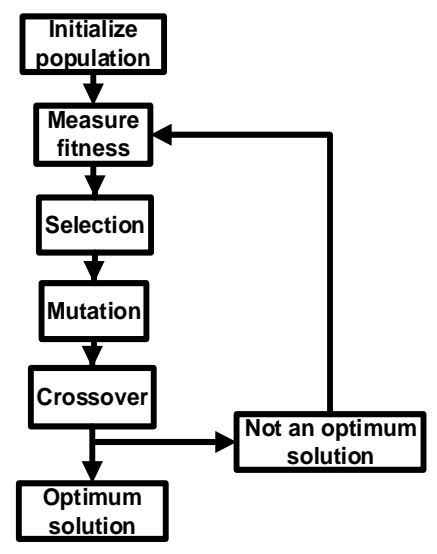

Figure 3. GA flow chart [25]

\section{RESULTS}

The PMDCM parameters are listed in Table1,

Table1. PMDCM parameters

\begin{tabular}{ccc}
\hline PMDCM parameters & Symbol & Value \\
\hline Power of motor shaft & $P$ & $5 \mathrm{~kW}$ \\
Rotor Resistance & $R_{a}$ & $0.5 \Omega$ \\
Rotor Inductance & $L_{a}$ & $0.012 \mathrm{H}$ \\
Moment of İnertia & $J_{m}$ & $0.00471 \mathrm{Kg} . \mathrm{m}^{2}$ \\
Friction constant & $B_{m}$ & $0.002 \mathrm{~N} . \mathrm{m} . \mathrm{s} / \mathrm{rad}$ \\
Motor Constant & $K_{b} K_{t}$ & 0.5 \\
\hline
\end{tabular}

PMDCM model is simulated based on motor equations (see section 2). The motor model is done using MATLAB-toolbox.

PMDCM complete speed control system is done with derivative feedback controller. The controller parameters are tuned based DS and GA strategies. The controller tuning is based on different performance 
indices to show the robustness of the proposed techniques. DS and GA algorithm parameters that are used in this work are listed in Table2 while the obtained controller parameters are listed in Table 3. The used performance indices are:

1) JISE (Integral-Square-Error).

2) JIAE (Integral-Absolute-Error).

3) JITAE (Integral-Time-Weighted-Absolute-Error).

4) JITSE (Integral-Time-Weighted-Square-Error).

Table 2. DS and GA parameters

\begin{tabular}{cccc}
\hline DS & Parameters & GA & Parameters \\
\hline Poll method & GPS positive basis 2N & Population & 100 \\
Correction-factor & 0.5 & Mutation-rate & 0.01 \\
No. of iteration & 50 & No. of generation & 50 \\
Penalty-factor & 100 & Crossover-Ratio & 1.2 \\
\hline
\end{tabular}

Table 3. Controller parameters

\begin{tabular}{cccccc}
\hline GA & $\mathrm{K}_{1}$ & $\mathrm{~K}_{2}$ & $\mathrm{DS}$ & $\mathrm{K}_{1}$ & $\mathrm{~K}_{2}$ \\
\hline JISE & 152.8770 & 0.0962 & JISE & 76.9319 & 1.0097 \\
JIAE & 812.7630 & 0.2914 & JIAE & 43.5927 & 0.4636 \\
JITSE & $3.74559 \mathrm{e}+03$ & 0.5514 & JITSE & 35.4620 & 0.4441 \\
JITAE & $1.98917 \mathrm{e}+04$ & 0.6163 & JITAE & 80.0309 & 0.8626 \\
\hline
\end{tabular}

Figure.4 illustrate the speed responses of PMDCM with proposed controller-based DS and GA techniques. While Figure. 5 shows a comparison in motor speed based all used performance criteria using DS and GA respectively.

2.

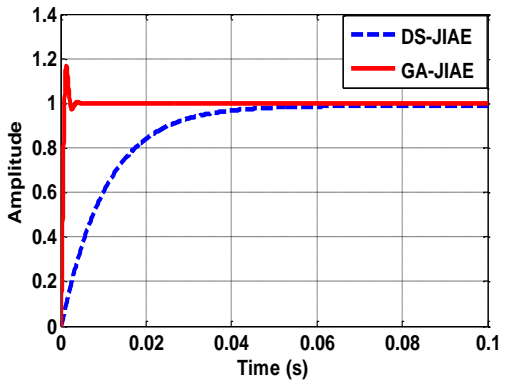

(a)

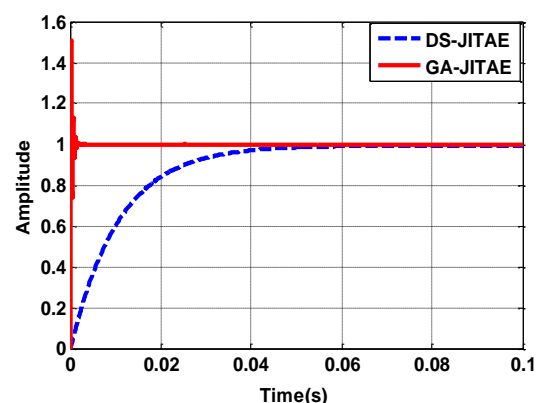

(c)

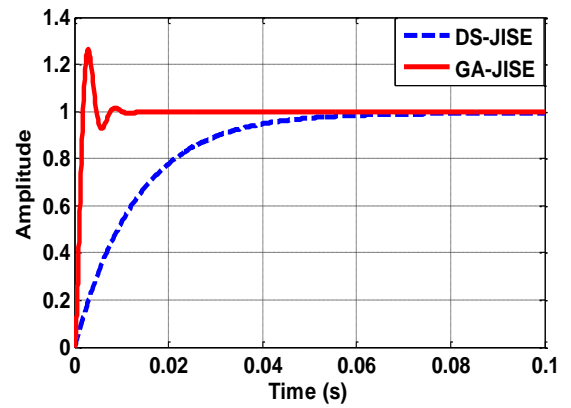

(b)

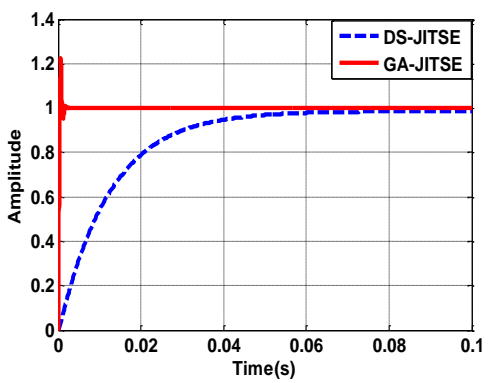

(d)

Figure 4. Motor response with controller optimized based the two optimization methods based (a) JIAE (b) JISE (c) JITAE (d) JITSE 
The obtained results clarify that, the proposed tuning techniques for controller tuning is do best for all performance indices. The system behavior is improved when using the proposed controller. The proposed controller that tuned using GA method reduce the response settling time largly but in the same time gives some overshoot because of forward gain large value. DS methods cause the response to slower settling with zero over shoot because of the balance between the gain of feedforward and feedback. The steady state error is eliminated when using the proposed controller-based DS and GA. The two-optimization techniques give best results and optimize the parameters of the proposed controller in order to to meet the requirements of the system.

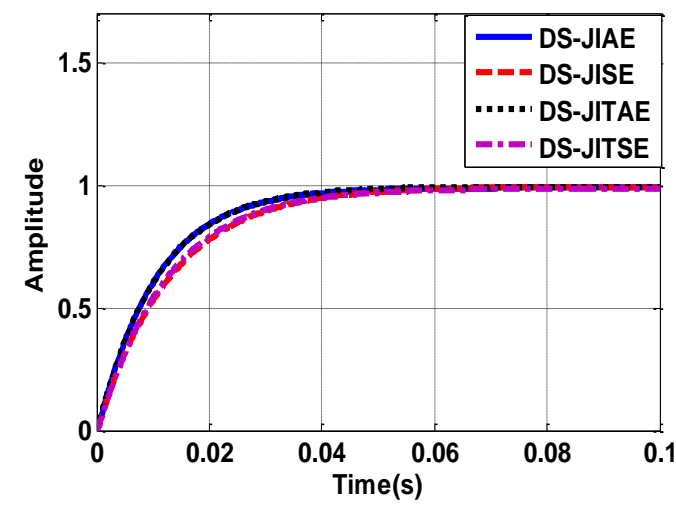

6.

(a)

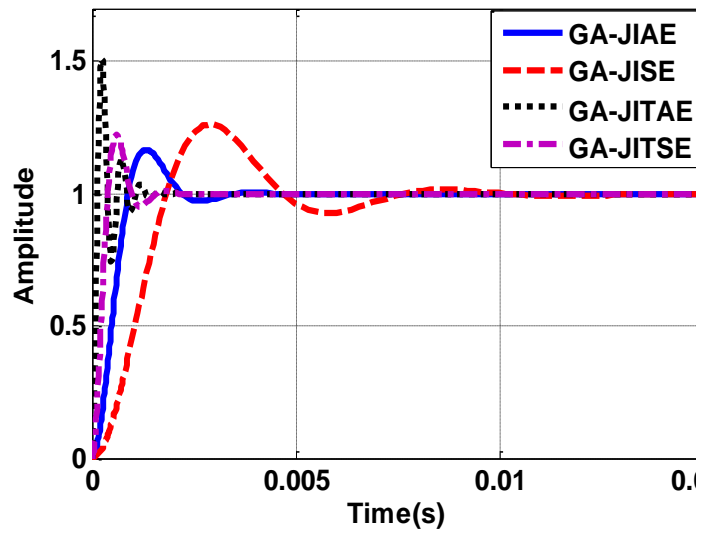

(b)

Figure 5. Comparison of the motor response based (a) DS (b) GA

Figure6 and Figure7 illustrate cost function plot and algorithm mesh size plot for DS strategy respectively. While Figure.8 and Figure.9 illustrate cost function plot and average distance between populations plot for GA strategy respectively.

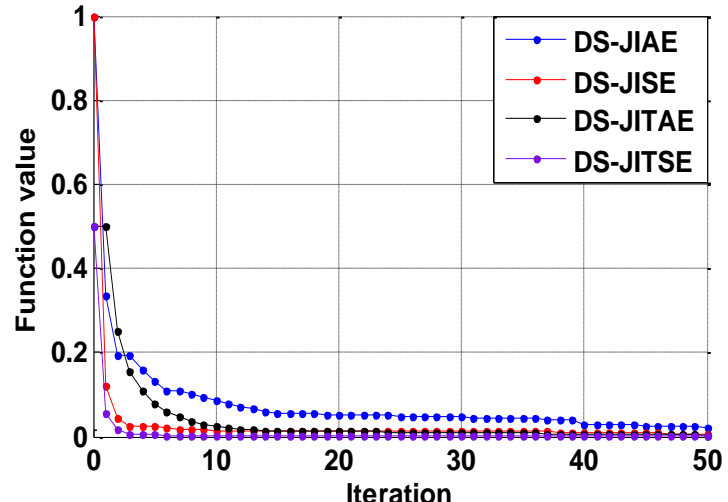

Figure 6. Cost-function plot based DS

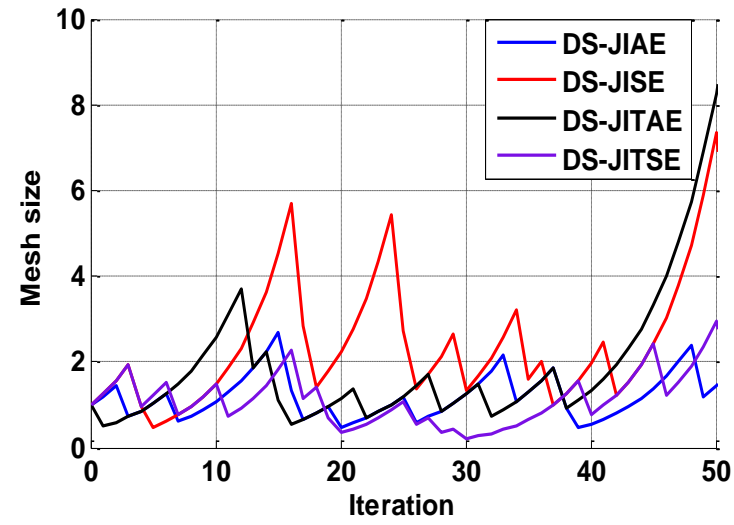

Figure 7. Plot of Mesh-size based DS 


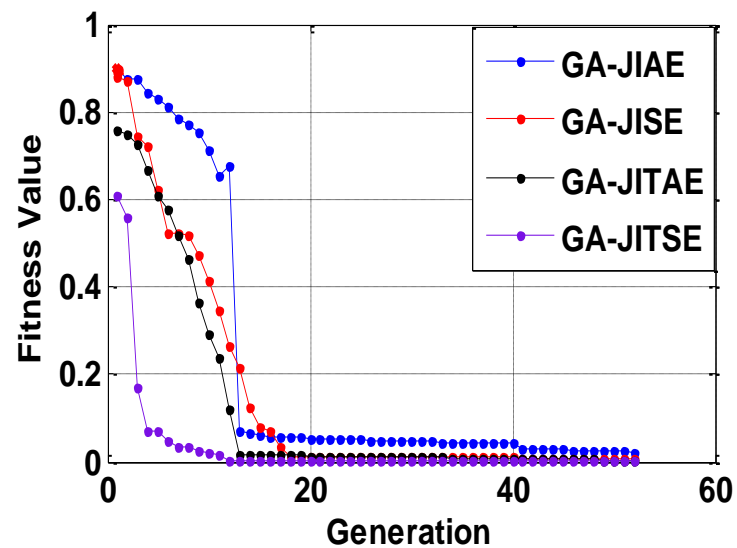

Figure 8. Plot of cost-function based GA

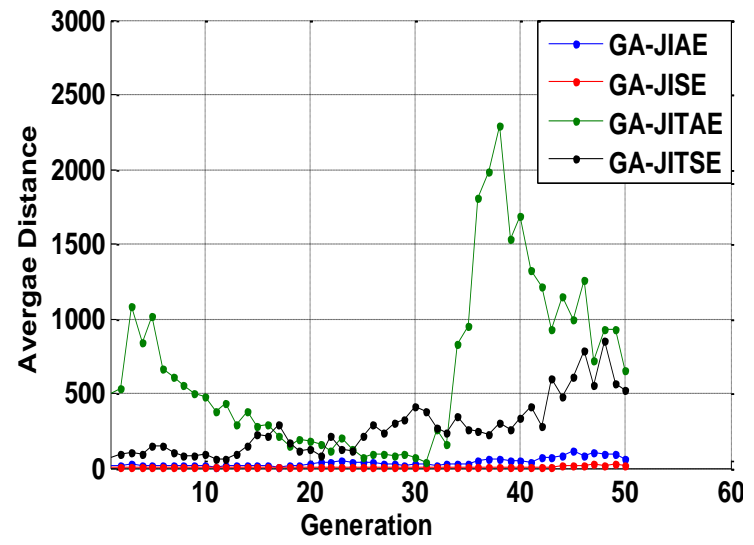

Figure 9. Generation average-distance based GA

For the two proposed optimization techniques it is clear that they have good fast convergence ability. DS strategy converge after pass10 iterations while GA strategy converge after pass 17 iterations approx. This properity of requiring lower iteration number make them fast convergence algorithm. While other optimization algorithms need large iteration number thatmake them lower convergence algorithms.

\section{CONCLUSIONS}

Output derivative controller is applicable largly in different industrial applications. It has good characteristics like easy to implement, simple structure, lower cost, lower complexity and have the ability to improve system behavior. In this work, the proposed controller is used for PMDCM speed control. DS and GA techniques are proposed for controller tuning in order to enhance system performance. The speed response of PMDCM with controller tuned based GA technique is faster and generate system overshoot for all performance criterias. While the response obtained with controller tuned based DS have produce slower speed response with zero system overshoot for all performance criterias. The system performance is enhanced base both proposed tuning techniques. Smallest peak, rise and settling time are obtained when using JIAE performance criteria base GA optimization strategy. While smallest peak, rise and settling time are obtained when using JITAE performance criteria base DS optimization strategy. So each performance criteria have its own advantages and disadvantages.

\section{REFERENCES}

[1] W. N. Abed, "Design of Armature and Field Control Systems based Bacterial Foraging Optimization Technique for Speed Control of DC Motor," International Journal of u- and e-Service, Science and Technology, vol. 8, pp. 385394, 2015.

[2] G. Shahgholian, P. Shafaghi, and T. nd International Conference on Electronic Computer, "State space modeling and eigenvalue analysis of the permanent magnet DC motor drive system," pp. 63-67, 2010.

[3] E. Elbakush, "A PREDICTIVE DYNAMIC CONTROLLER FOR PMDC MOTOR DRIVERS."

[4] A. Ambrisi, M. Demagistris, and R. Fresa, "Multi-objective Optimization Based Design of High Efficiency DC-DC Switching Converters," International Journal of Power Electronics and Drive Systems, vol. 7, p. 379, 2016.

[5] I. MathWorks, Genetic algorithm and direct search toolbox : for use with MATLAB. Natick, Mass.: Math Works, 2007.

[6] T. A. Sriver, J. W. Chrissis, and M. A. Abramson, "Pattern search ranking and selection algorithms for mixed variable simulation-based optimization," EOR European Journal of Operational Research, vol. 198, pp. 878-890, 2009.

[7] G. A. M. Ismeal, K. Kyslan, and V. Fedák, "CAD of Cascade Controllers for DC Drives Using Genetic Algorithm Methods," PROENG Procedia Engineering, vol. 96, pp. 182-189, 2014.

[8] C. Copot, C.I. Muresan, and R. D. Keyser, "Speed and position control of a DC motor using fractional order PI-PD control," presented at the 3rd International Conference on Fractional Signals and Systems - FSS 2013, Ghent, Belgium, 2013.

[9] D. Puangdownreong, A. Nawikavatan, and C. Thammarat, "Optimal Design of I-PD Controller for DC Motor Speed Control System by Cuckoo Search," Procedia Computer Science Procedia Computer Science, vol. 86, pp. 83-86, 2016. 
[10] D. Singh, B. Singh, and N. Singh, "Performance indices based optimal tunining criterion for speed control of DC drives using GA," Int. J. Power Electron. Drive Syst. International Journal of Power Electronics and Drive Systems, vol. 4, pp. 461-473, 2014.

[11] H. E. A. Ibrahim and A. A. Hakim Mahmoud, "DC motor control using PID controller based on improved ant colony algorithm," Int. Rev. Autom. Control International Review of Automatic Control, vol. 7, pp. 1-6, 2014.

[12] H. E. A. Ibrahim, F. N. Hassan, and A. O. Shomer, "Optimal PID control of a brushless DC motor using PSO and BF techniques," Ain Shams Engineering Journal Ain Shams Engineering Journal, vol. 5, pp. 391-398, 2014.

[13] D. Sandoval, I. Soto, P. Adasme, E. E. I. Chilean Conference on Electrical, and T. Communication, "Control of direct current motor using Ant Colony optimization," pp. 79-82, 2015.

[14] S. K. Suman, V. K. Giri, I. I. C. o. Engineering, and Technology, "Speed control of DC motor using optimization techniques based PID Controller," pp. 581-587, 2016.

[15] A. Abdulameer, M. Sulaiman, M. S. M. Aras, and D. Saleem, "Tuning methods of PID controller for DC motor speed control," Indones. J. Electrical Eng. Comput. Sci. Indonesian Journal of Electrical Engineering and Computer Science, vol. 3, pp. 343-349, 2016.

[16] M. A. Shamseldin, M. A. A. Ghany, and A. M. A. Ghany, "Performance study of enhanced non-linear PID control applied on brushless DC motor," Int. J. Power Electron. Drive Syst. International Journal of Power Electronics and Drive Systems, vol. 9, pp. 536-545, 2018.

[17] T. Murat, F. Can Bülent, K. Süreyya, and G. r. 1. Sertaç, "Effective and Reliable Speed Control of Permanent Magnet DC (PMDC) Motor under Variable Loads," Journal of Electrical Engineering \& Technology, vol. 10, pp. 2170-2178, 2015.

[18] U. S. Bakshi and S. C. Goyal, Feedback control systems: Technical Publications Pune, 2002.

[19] A. K. Ghosh, Introduction to linear and digital control systems. New Delhi: Prentice-Hall of India, 2007.

[20] A. Nassirharand and S. C. Li, "Nonlinear Proportional and Rate Feedback Controller Design Synthesis with Experimental Verification," J. Aerosp. Eng. Journal of Aerospace Engineering, vol. 27, 2014.

[21] A. I. Vaz and L. s. Vicente, "A particle swarm pattern search method for bound constrained global optimization," JOURNAL OF GLOBAL OPTIMIZATION, vol. 39, pp. 197-219, 2007.

[22] J. S. Al-Sumait, A. K. Al-Othman, and J. K. Sykulski, "Application of pattern search method to power system valve-point economic load dispatch," International Journal of Electrical Power \& Energy Systems International Journal of Electrical Power \& Energy Systems, vol. 29, pp. 720-730, 2007.

[23] R. Taleb, D. Benyoucef, and Z. Boudjema, "Genetic algorithm application in asymmetrical 9-level inverter," International Journal of Power Electronics and Drive Systems, vol. 7, p. 521, 2016.

[24] M. Kanai, J. Nderu, and P. Hinga, "Adaptive PID DC motor speed controller with parameters optimized with hybrid optimization strategy," in 2nd International conference on Advances in Engineering and Technology, 2011.

[25] A. Jayachitra and R. Vinodha, "Genetic Algorithm Based PID Controller Tuning Approach for Continuous Stirred Tank Reactor," Advances in Artificial Intelligence Advances in Artificial Intelligence, vol. 2014, pp. 1-8, 2014.

\section{BIOGRAPHIES OF AUTHORS}

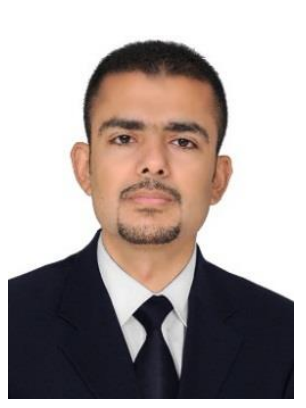

The Lecturer Wisam Najm AL-Din Abed received a bachelor's degree in electrical power and machines from engineering college-Diyala University in 2005 and received a master's degree in electrical engineering / power from the University of Technology in 2011. area of research interest in the electric power, machinery and control engineering and artificial intelligence and algorithms Engineering Optimization. He has more than scientific research published in local and international journals.

Email: wisam_alobaidee@yahoo.com

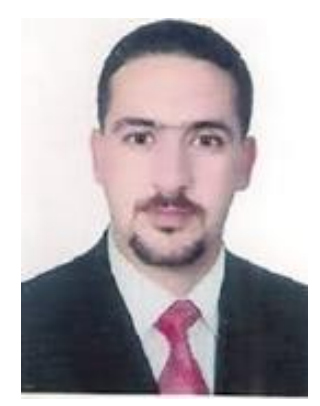

The Lecturer Adham Hadi Saleh received a bachelor's degree in electronic engineering from Diyala University in 2006 and received a master's degree in Electrical Engineering / Electronic from the University of Technology in 2012. Work in SAKAR company - electrical generation station. The area of research interest in the design of systems using VHDL Artificial intelligence and image processing and digital signal processing. He has more than scientific research published in local and international journals.

Email: adham.hadi@yahoo.com 


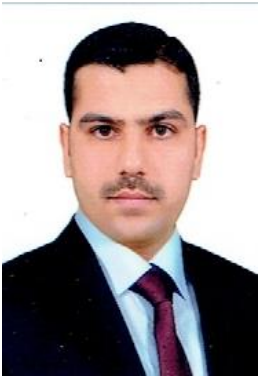

The Lecturer Abbas Salman Hameed received a bachelor's degree in electronic engineering from Diyala University in 2006 and received a master's degree in electronics and communications engineering from Al-Mustansiriya University in 2012. the field of research interest in the image and video signal processing and wireless communications systems. He has more than scientific research published in local and international journals.

Email: abbasfuture@yahoo.com 